\title{
CD56 in the Immune System: More Than a Marker for Cytotoxicity?
}

\author{
Heleen H. Van Acker ${ }^{1 *}$, Anna Capsomidis ${ }^{2}$, Evelien L. Smits ${ }^{1,3,4}$ and Viggo F. Van Tendeloo ${ }^{1}$ \\ 'Laboratory of Experimental Hematology, Tumor Immunology Group (TIGR), Faculty of Medicine and Health Sciences, \\ Vaccine \& Infectious Disease Institute (VAXINFECTIO), University of Antwerp, Antwerp, Belgium, ${ }^{2}$ Cancer Section, UCL Great \\ Ormond Street Institute of Child Health, London, United Kingdom, ${ }^{3}$ Center for Cell Therapy and Regenerative Medicine, \\ Antwerp University Hospital, Edegem, Belgium, ${ }^{4}$ Center for Oncological Research (CORE), Faculty of Medicine and Health \\ Sciences, University of Antwerp, Antwerp, Belgium
}

\section{OPEN ACCESS}

Edited by:

Rene De Waal Malefyt,

Merck Research Laboratories,

United States

Reviewed by:

Evelyn Ullirich,

Goethe University Frankfurt, Germany

David B. Rosen,

Merck Research Laboratories,

United States

*Correspondence:

Heleen H. Van Acker

heleen.vanacker@uantwerp.be

Specialty section:

This article was submitted to

T Cell Biology,

a section of the journal

Frontiers in Immunology

Received: 27 May 2017

Accepted: 12 July 2017

Published: 24 July 2017

Citation:

Van Acker HH, Capsomidis A,

Smits EL and Van Tendeloo VF (2017)

CD56 in the Immune System: More

Than a Marker for Cytotoxicity?

Front. Immunol. 8:892.

doi: 10.3389/fimmu.2017.00892
Over the past years, the phenotypic and functional boundaries distinguishing the main cell subsets of the immune system have become increasingly blurred. In this respect, CD56 (also known as neural cell adhesion molecule) is a very good example. CD56 is the archetypal phenotypic marker of natural killer cells but can actually be expressed by many more immune cells, including alpha beta T cells, gamma delta T cells, dendritic cells, and monocytes. Common to all these CD56-expressing cell types are strong immunostimulatory effector functions, including Thelper 1 cytokine production and an efficient cytotoxic capacity. Interestingly, both numerical and functional deficiencies and phenotypic alterations of the CD56 immune cell fraction have been reported in patients with various infectious, autoimmune, or malignant diseases. In this review, we will discuss our current knowledge on the expression and function of CD56 in the hematopoietic system, both in health and disease.

Keywords: CD56, cellular immune response, interleukin-15, neural cell adhesion molecule, natural killer cell, T cell

\section{INTRODUCTION}

The neural cell adhesion molecule (NCAM), also known as CD56, is a member of the immunoglobulin superfamily engaged in both so-called homophilic and heterophilic interactions. Three main isoforms exist of CD56 (NCAM-120, NCAM-140, and NCAM-180), all generated by alternative splicing from one single gene, differing in their intracellular domain length (1). CD56 is often considered a marker of neural lineage commitment due to its discovery site (2). However, CD56 expression is also found in, among others, the hematopoietic system. Here, the expression of CD56 is most stringently associated with, but certainly not limited to, natural killer (NK) cells (Figure 1) (3). CD56 has been detected on other lymphoid cells, including gamma delta $(\gamma \delta)$ T cells and activated $\mathrm{CD} 8^{+} \mathrm{T}$ cells, as well as on dendritic cells (DCs) (4-6). Also, in the bone marrow, at the site where hematopoiesis occurs, CD56 fulfills a pivotal role. Mesenchymal stromal cells provide niches for hematopoietic stem cells by, inter alia, the expression of adhesion molecules comprising CD56, maintaining long-term hematopoiesis $(7,8)$. On the other hand, aberrant CD56 expression is seen in a range of hematological malignancies [e.g., multiple myeloma and leukemia $(9,10)]$ as well as solid tumors [e.g., lung cancer, ovarian cancer, and neuroblastoma (11-13)].

Abbreviations: CIK, cytokine-induced killers; CTL, cytotoxic T lymphocyte; DC, dendritic cell; $\gamma \delta \mathrm{T}$ cell, gamma delta T cell; HSCT, hematopoietic stem cell transplantation; IFN, interferon; IL, interleukin; ILC, innate lymphoid cell; IPP, isopentenyl pyrophosphate; KIR, killer cell Ig-like receptor; lnc, long non-coding; NCAM, neural cell adhesion molecule; NK cell, natural killer cell; TCR, T cell receptor; TEMRA, terminally differentiated CD45RA (CD8+) T cells; TIL, tumor-infiltrating lymphocytes; TRAIL, TNF-related apoptosis-inducing ligand. 


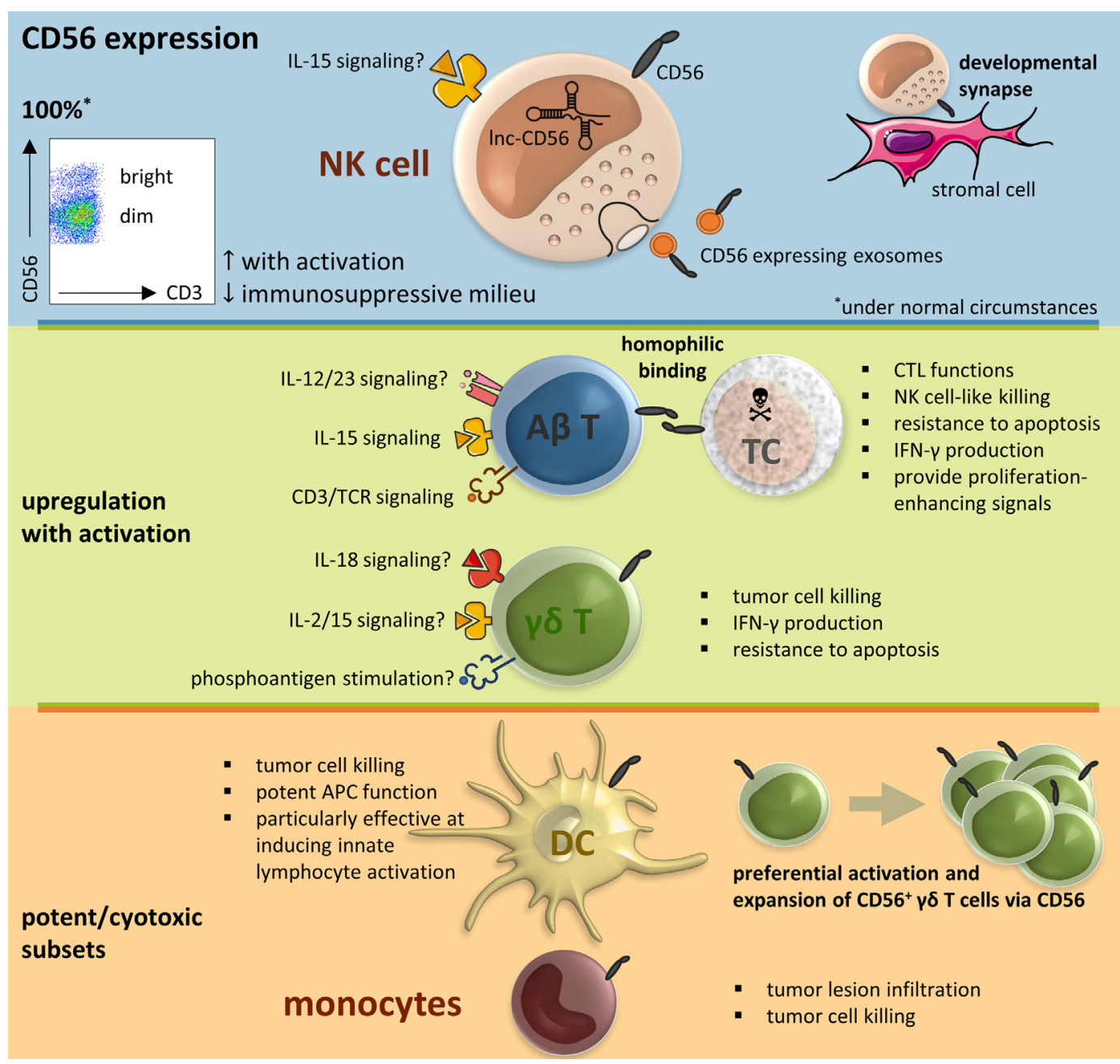

FIGURE 1 | CD56 in the immune system, resumptive figure. Abbreviations: $\alpha \beta$ T, alpha beta T cell; $\gamma \delta$ T, gamma delta T cell; APC, antigen-presenting cell; CTL, cytotoxic T lymphocyte; DC, dendritic cell; IL, interleukin; IFN, interferon; Inc, long non-coding; NK cell, natural killer cell; SC, stressed cell; TCR, T cell receptor.

Moreover, numerical and functional deficiencies and phenotypic alterations of $\mathrm{CD} 56^{+}$immune cells have been reported in patients with various infectious, autoimmune or malignant diseases (Table 1).

\section{CD56 EXPRESSION ON HUMAN IMMUNE CELLS IN HEALTH AND DISEASE}

\section{NK Cells}

Natural killer cells are prototypic members of the innate lymphoid cell (ILC) family and characterized in humans by expression of the phenotypic marker CD56 in the absence of CD3. They are usually further divided into two subsets based on their surface level expression of CD56 (3). Whereas most NK cells in peripheral blood are CD56 ${ }^{\mathrm{dim}}, \mathrm{CD} 56^{\text {bright }} \mathrm{NK}$ cells are more abundant in tissues. Until recently it was widely believed that CD56 $6^{\text {bright }} \mathrm{NK}$ cells were superior at producing pro-inflammatory cytokines, and CD56 ${ }^{\mathrm{dim}} \mathrm{NK}$ cells were described as the more cytotoxic subset. Rather, CD56 $6^{\text {bright }} \mathrm{NK}$ cells respond better to soluble factors, while the $\mathrm{CD} 56^{\mathrm{dim}}$ subset responds better to receptors binding ligands anchored on other cells (35). NK cells have a central role in the cellular immune response, comprising tumor-cell surveillance as demonstrated in the setting of hematopoietic stem cell transplantation (HSCT). The discovery of donor-derived alloreactive NK cells present in T-cell-depleted HLA haploidentical grafts for HSCT was a milestone in the field of NK cell therapy (36-38).

To date, the reason why NK cells, and immune cells in general, express CD56 remains unanswered. However, there is a clear relationship with the degree of activation. Expression of CD56 can therefore be used as a phenotypic activation marker, similar to the use of CD69 and HLA-DR (39-41). For example, upon DC vaccine-mediated activation, both CD56 $6^{\text {bright }}$ and CD56 $6^{\mathrm{dim}}$ NK cell subsets upregulate their expression of $\operatorname{CD} 56(39,41)$. The same applies for expanded NK cells prepared for adoptive transfer using artificial antigen-presenting cells (40). It should therefore come as no surprise that regulatory DCs, in contrast to 
TABLE 1 | CD56 expression on immune cells in disease.

\begin{tabular}{|c|c|c|c|}
\hline Disease & Cell type & Effect & Reference \\
\hline \multicolumn{4}{|l|}{ Cancer } \\
\hline Cancer (general) & Monocytes & $\uparrow$ higher numbers & (14) \\
\hline Metastatic melanoma & Alpha beta $(\alpha \beta)$ T cells & $\uparrow$ in patients responding to anti-PD-1 therapy & (15) \\
\hline (Advanced) solid tumors & $\alpha \beta$ T cells & $\begin{array}{l}\uparrow \text { after immunoradiotherapy } \rightarrow \text { injecting } \mathrm{CD} 56^{+} \text {cytotoxic } T \text { lymphocytes } \\
(\mathrm{CTLS}) \uparrow \text { complete remissions }\end{array}$ & $(16)$ \\
\hline Bladder cancer & Natural killer (NK) cells & $\uparrow$ in bacillus Calmette-Guérin-treated patients & $(17)$ \\
\hline Head and neck squamous cell carcinoma & Dendritic cells (DCs) & CD56+ DC subsets are absent in metastatic lymph nodes & (18) \\
\hline Hepatocellular carcinoma & $\alpha \beta$ T cells & $\begin{array}{l}\text { FOXP3 }{ }^{+} \mathrm{CD} 3^{+} \mathrm{CD} 4^{+} \mathrm{CD} 56^{+} \text {tumor-infiltrating lymphocytes inversely correlate } \\
\text { with survival }\end{array}$ & $(19)$ \\
\hline Hepatic metastases of colonic origin & Gamma delta $(\gamma \delta)$ T cells & $\uparrow$ expression of CD56 & (20) \\
\hline Papillary thyroid carcinoma & Monocytes & CD14+CD56 ${ }^{+}$monocytes infiltrate into tumor lesions & (14) \\
\hline Acute myeloid leukemia & $\gamma \delta \mathrm{T}$ cells & $\uparrow$ expression of CD56 & (6) \\
\hline Asymptomatic myeloma & NK cells & $\uparrow$ expression in patients receiving low-dose lenalidomide and DC therapy & $(21)$ \\
\hline \multicolumn{4}{|l|}{ Infectious diseases } \\
\hline \multirow[t]{3}{*}{ HIV } & NK cells & Dysfunctional CD56- NK cells & $(22)$ \\
\hline & $\alpha \beta$ T cells & CD56 $^{+}$CD8 ${ }^{+} T$ cell depletion, but not in natural virus suppressors & (23) \\
\hline & $\gamma \delta \mathrm{T}$ cells & $\mathrm{CD} 6^{+} \gamma \delta \mathrm{T}$ cell depletion, but not in natural virus suppressors & (24) \\
\hline \multirow[t]{2}{*}{ Chronic hepatitis C } & NK cells & Dysfunctional CD56- NK cells & (25) \\
\hline & $\gamma \delta \mathrm{T}$ cells & $\uparrow$ expression of CD56 & (26) \\
\hline Cytomegalovirus & NK cells & Dysfunctional CD56- NK cells & (27) \\
\hline Hantavirus & NK cells & Dysfunctional CD56- ${ }^{-}$NK cells & $(28)$ \\
\hline \multicolumn{4}{|l|}{ Autoimmune disorders } \\
\hline Crohn's disease & Monocytes & $\uparrow$ higher numbers & (29) \\
\hline \multirow[t]{2}{*}{ Multiple sclerosis } & $\alpha \beta$ T cells & Myelin-specific CD56+CD4+ T cells kill oligodendrocytes & (30) \\
\hline & $\alpha \beta$ T cells & Fingolimod $\uparrow{\text { CD } 56^{+}}^{+} \uparrow$ cells in peripheral blood & $(31)$ \\
\hline Systemic sclerosis & $\alpha \beta$ T cells & $\uparrow$ CD56+ CTL recruitment to affected tissues & (32) \\
\hline Ocular myasthenia gravis & NK cells & Dysfunctional CD56- NK cells & (33) \\
\hline Psoriasis & $\alpha \beta$ T cells & $\uparrow$ CD56 $^{+}$CTL recruitment to affected tissues & (32) \\
\hline Rheumatoid arthritis & Monocytes & $\uparrow$ higher numbers $\rightarrow$ treatment with etanercept $\downarrow=$ better response & $(34)$ \\
\hline
\end{tabular}

their mature immunostimulatory counterparts, lack the ability to upregulate the expression of CD56 on CD56 dim NK cells (42). Moreover, this applies not only for DC-mediated NK cell stimulation. Upon activation, CD56 ${ }^{\mathrm{dim}} \mathrm{NK}$ cells can adopt a CD56 $6^{\text {bright }}$ like immunophenotype or upregulate their CD56 expression in general $(17,21,43,44)$. Conversely, NK cells exposed to an immunosuppressive milieu downregulate their CD56 expression, concomitant with abolition of their cytotoxicity (45). This is, among others, demonstrated for factors present in plasma of chronic lymphocytic leukemia patients (45). In support of the functional role of CD56, exosomes released by NK cells express CD56 as well (46). Since exosomes are cell-derived vesicles, conceivably having a role in the immune response, the expression of CD56 serves by all odds a purpose, just like the enclosed killer proteins (i.e., FasL, perforin) (46). One possible role could be, for example, the adhesion of the NK cell exosomes to target cells (47).

Lastly, it should be noted that there also exists a CD56 ${ }^{-} \mathrm{NK}$ cell subpopulation, namely $\mathrm{CD} 3{ }^{-} \mathrm{CD} 4^{-} \mathrm{CD} 14^{-} \mathrm{CD} 19^{-} \mathrm{CD} 16^{+} \mathrm{NKp} 46^{+}$ lymphocytes $(25,48)$. While $\mathrm{CD}^{-} 6^{-} \mathrm{NK}$ cells are rarely found in healthy individuals (25), elevated levels of $\mathrm{CD}^{-} 6^{-} \mathrm{NK}$ cells are commonly found in patients with several pathological conditions, including HIV (22), chronic hepatitis C (25), human cytomegalovirus (27) and hantavirus infections (28), autoimmune disorders (33), and following hematopoietic (stem) cell transplantation $(49,50)$. In all these diverse settings, CD56 ${ }^{-}$ NK cells are reported to be dysfunctional or impaired with reference to their cytolytic capacity and cytokine production. Unfortunately, aging per se may also have a deleterious effect on the functional capacity of NK cells. A redistribution of NK cell subsets is confirmed in the elderly, whereby the proportion of the dysfunctional CD56- NK cell subset is increased (51). Altogether, these data emphasize the association between CD56 expression and NK effector function.

\section{$\alpha \beta$ T Cells}

The cell-mediated adaptive immune response is primarily attributable to conventional T cells. CD56 expression on these $\alpha \beta$ T cells is, similar to NK cells, associated with potent effector function in the human intestine, liver, and peripheral blood (52-54). More specifically, CD56 surface expression on T cells correlates well with expression of CD16, NKG2A/D, NKp44/46, CD122, and DNAM-1, a high intracytoplasmic perforin and granzyme B content, and $\mathrm{CD}^{+}$cytotoxic T lymphocyte (CTL) functions $(23,53-57)$. Moreover, $\mathrm{CD}^{+} 6^{+} \mathrm{T}$ cells are able to exert NK cell-like killing activity in a pro-inflammatory milieu $(54,57)$. This property is mainly due to killer cell Ig-like receptor (KIR) ${ }^{+}$ cells within the $\mathrm{CD}^{2} 6^{+} \mathrm{T}$ cell fraction (57). All the aforementioned suggests a link between CD56 acquisition by T cells with increased T cell receptor (TCR)-mediated and NK-like cytotoxic potential. Since CD56 also correlates with the expression of the anti-apoptotic protein $\mathrm{Bcl}-2$, increased resistance to apoptosis is advocated (54). Second, CD56 ${ }^{+} \mathrm{T}$ cells share with NK cells 
the capacity to produce interferon (IFN) $-\gamma$ upon interleukin (IL)-15 or IL-12 + IL-18 treatment (53). This pro-inflammatory cytokine production is also seen after stimulation with other immune activating signals such as stimulation of CD3 (4), engagement of the cell adhesion molecule CD2 (LFA-1) (52), or the presence of infectious pathogens. For example, CD56 ${ }^{+} \mathrm{T}$ cells produce IFN- $\gamma$ in the presence of Bacillus Calmette-Guérin, as well as in response to Salmonella typhimurium-infected macrophages (53). This pro-inflammatory cytokine response is, on the other hand, barely detectable in their CD56 ${ }^{-}$counterparts (53). Furthermore, regulatory (IL-10) and T helper 2 (IL-4 and IL-5) cytokine production by $\mathrm{CD}^{+} 6^{+} \mathrm{T}$ cells is marginal (4, 52). Next, mucosal CD56 ${ }^{+} \mathrm{T}$ cells exhibit a compromised proliferation potential as compared to their $\mathrm{CD}^{-} 6^{-}$counterparts, characteristic for their mature state (52). Nevertheless, CD56 ${ }^{+}$ $\mathrm{T}$ cells provide proliferation-enhancing signals following global activation to other immune cells, mediating-immune responses in a contact-dependent manner (52).

These properties make $\mathrm{CD}^{+} 6^{+} \mathrm{T}$ cells attractive potential targets for therapy for infectious and immune-mediated diseases as well as cancer. For example, in metastatic melanoma, a distinct population of $\mathrm{T}$ cells with high expression of HLA-DR and CD56 increased by ninefold in patients responding to anti-PD-1 therapy (15). In line with this, immunoradiotherapy augmented the abundance of circulating $\mathrm{CD}^{+} \mathrm{CD} 56^{+}$cells in advanced cancer patients (16). Interestingly, injecting patients who failed to respond to immunoradiotherapy with $\mathrm{CD} 56^{+} \mathrm{CTL}$ into their recurrent metastatic lesions resulted in $59 \%$ of complete remissions at these sites (16). On this note, we would like to touch on cytokine-induced killers (CIK) cells that fall within this group of NK cell-like $\mathrm{T}$ lymphocytes, whereby the CD56 ${ }^{+} \mathrm{CIK}$ cells represent the cell type with the highest tumor killing abilities $(58,59)$. Although CIK cells are beyond the scope of this review, we would like to direct the reader to Schmeel et al. (59) and Mesiano et al. (58) for a comprehensive review.

Proceeding to infectious diseases, CD56-expressing CD8 ${ }^{+}$ $\mathrm{T}$ cells were found to be depleted in $\mathrm{HIV}^{+}$patients (on therapy), but not in natural virus suppressors, i.e., elite patients suppressing HIV replication without antiretroviral therapy (23). This could be of importance bearing in mind that antiretroviral therapy to date, showing effective HIV suppression and reconstitution of CD4 $\mathrm{T}$ cells, still fails to restore $\mathrm{CD} 8^{+} \mathrm{T}$ cell lytic effector functions needed to eradicate the viral reservoir. One reason behind this loss of $\mathrm{CD} 56^{+} \mathrm{T}$ cells could be the high expression of the exhaustion marker TIM-3 on CD56 ${ }^{+} \mathrm{T}$ cells of HIV patients, whereas this is not seen for $\mathrm{CD}^{2} 6^{+} \mathrm{T}$ cells of elite patients. Immune exhaustion is therefore a potential mechanism for preferential depletion of $\mathrm{CD}^{+}{ }^{+} \mathrm{CD}^{+} \mathrm{T}$ cells $(23)$.

Regarding autoimmune diseases, patients suffering from systemic sclerosis, mainly those with active/late capillaroscopic patterns or with severe lung impairment, have decreased numbers of circulating $\mathrm{CD} 6^{+}$CTLs as compared to healthy individuals (60). Even though different mechanisms may be involved, this decline in CD56 ${ }^{+} \mathrm{T}$ cells in the peripheral blood results at least in part from the recruitment and/or trafficking of these cells to the affected tissues, where they cause endothelial cell injury and apoptosis (32). The decrease in $\mathrm{CD}^{+} 6^{+} \mathrm{T}$ cell counts is furthermore not only a characteristic of scleroderma but also of other autoimmune disease, for example, of psoriasis (32). In addition, in multiple sclerosis, cytotoxic myelin-specific $\mathrm{CD} 6^{+} \mathrm{CD} 4^{+} \mathrm{T}$ cells were described, killing oligodendrocytes in a NKG2C-mediated manner (30). It should therefore be noted that not only CD $56^{+}$CTLs but also cytotoxic $\mathrm{CD} 56^{+} \mathrm{CD} 4^{+} \mathrm{T}$ cells do exist, lying at the root of the pathogenesis of disease. As a consequence, the impact of (novel) treatment strategies for multiple sclerosis on the $\mathrm{CD}^{2} 6^{+}$immune cell fraction is of importance. Fingolimod, a sphingosine 1-phosphate receptor modulator, is indicated as single disease-modifying therapy in highly active relapsing remitting multiple sclerosis patients. Notably, it turns out that fingolimod therapy increases the frequency of CD56 ${ }^{+}$ $\mathrm{T}$ cells in peripheral blood in multiple sclerosis patients, particularly during relapses (31).

In analogy with NK cells, aging induces weakening of the adaptive immune system, generally termed as immunosenescence $(61,62)$. This is accompanied by an accumulation of cells combining features of both the innate and adaptive arms of the immune system, most likely to compensate for functional defects of conventional $\mathrm{NK}$ and $\mathrm{CD} 8^{+} \mathrm{T}$ cells with age. In contrast to exhausted T cells, senescent terminally differentiated CD45RA $\left(\mathrm{CD} 8^{+}\right) \mathrm{T}$ (TEMRA) cells are effector $\mathrm{T}$ cells with complete competence. They develop features of NK cells comprising the upregulation of NK cell receptors, including CD56. TEMRA cells use their acquired NK cell machinery to maintain rapid effector functions throughout life, tackling the increased burden of tumors and infections in the elderly $(61,62)$.

As a final remark, not every $\mathrm{CD}^{2} 6^{+} \mathrm{T}$ cell exhibits by definition immune invigorating capacity. In the tumor bed of patients with hepatocellular carcinoma, a $\mathrm{FOXP}^{+} \mathrm{CD}^{+} \mathrm{CD} 4^{+} \mathrm{CD} 56^{+}$ population with immunosuppressive function has been found (similar to regulatory T cells) (19). In comparison, $\mathrm{FOXP}^{+}$cells were rarely detected in the $\mathrm{CD} 3^{+} \mathrm{CD} 56^{+}$population from adjacent non-cancerous tissues and were completely absent from normal liver tissues (19). The prevalence of $\mathrm{FOXP}^{+}{ }^{+} \mathrm{CD} 4^{+} \mathrm{CD} 56^{+} \mathrm{T}$ cells in tumor-infiltrating lymphocytes (TILs) was moreover found to be inversely correlated with patient survival (19). Besides FOXP3 ${ }^{+}$ TILs, other immune cell subsets may as well exert a powerful regulatory/suppressive influence upon the cell-mediated immune response. In human glioblastoma, a significant proportion of TILs were $\mathrm{CD} 3{ }^{+} \mathrm{CD} 4{ }^{+} \mathrm{CD} 56^{+}$immunosuppressive $\mathrm{T}$ cells (63). Here too, only a minority of $\mathrm{CD}^{+}$peripheral lymphocytes expressed CD56 (63). Other non-glial intracranial tumors, including meningioma and metastatic non-small cell lung cancer, showed however no accumulation of $\mathrm{CD}^{+} \mathrm{CD}^{+} 6^{+}$in the tumor (63). It is therefore necessary to take into account that the favorable profile of the $\mathrm{CD} 6^{+} \mathrm{T}$ cells is possibly depending on the $\mathrm{T}$ cell subset and/or is sensitive to changes by the tumor microenvironment, with variation between cancer types. Concerning the latter, special emphasis should be given to the expression levels of CD56 on the tumor cells, considering glioblastoma is known to express CD56, whereas, for example, non-small cell lung cancer generally does not.

\section{$\gamma \delta$ T Cells}

Gamma delta T cells are the prototype of "unconventional" T cells, defined by the expression of a TCR composed of an $\gamma$ and $\delta$ chain. 
Although they only constitute less than $5 \%$ of all T lymphocytes, their role in the immune system should not be underestimated. $\gamma \delta \mathrm{T}$ cells have a wide range of functional properties including innate killing, tumor tropism, the support of DC, T cell, and NK cell functions, and, as recently demonstrated, also antigen presentation skills (64-67). Moreover, the proportion of CD56 ${ }^{+}$ $\gamma \delta \mathrm{T}$ cells appears to be determined by their level of activation $(6,20)$.

Different signals are able to induce $\gamma \delta \mathrm{T}$ cell activation including phosphoantigens, cytokines, activating receptors, and TCR-mediated signals $(65,68-70)$. As leading example, stimulation of isolated $\gamma \delta$ T cells with isopentenyl pyrophosphate (IPP), a mevalonate-derived isoprenoid phosphoantigen, and the cytokines IL-2 or IL-15 leads to a significant upregulation of CD56 concomitant with CD69 and HLA-DR (6). Activation of $\gamma \delta$ T cells with IL-15 and isoprenoid pyrophosphates induces furthermore the expression of IL-15R $\alpha$, CD96, CD161, and perforin, all markers of cytotoxic cells (71). Stimulation of $\gamma \delta$ $\mathrm{T}$ cells from $\mathrm{HIV}^{+}$donors with IL-18 and IPP, results not only in $\gamma \delta \mathrm{T}$ cell proliferation but also in the higher expression of CD56, NKG2D, and CD107a (72). The cytotoxic phenotype of all these $\mathrm{CD}_{56}{ }^{+}$effector $\gamma \delta \mathrm{T}$ cells puts forward that CD56 may be a marker of true effector $\gamma \delta$ T cells. It is indeed expressed on a potently cytotoxic subset of human $\gamma \delta$ T cells. CD56-expressing, but not CD56-, IPP-expanded $\gamma \delta$ T cells kill head and neck squamous cell carcinoma through the perforin-granzyme pathway (73). Yet, CD56 neutralization itself did not affect $\mathrm{CD}^{+} 6^{+} \gamma \delta$ T cell-mediated killing of tumor cells (73). In addition to cytotoxicity, $\mathrm{CD} 56^{+}$effector $\gamma \delta \mathrm{T}$ cells rapidly produce large amounts of IFN- $\gamma$ upon stimulation (71) and have an increased resistance to Fas ligand and chemically induced apoptosis (73). Strikingly, expression of CD56 is strongest in non-proliferating $\gamma \delta \mathrm{T}$ cells and gradually disappears with the number of cell divisions (71). Taken together, CD56 defines $\gamma \delta$ T cells with increased antitumor activity, identifying a robust $\gamma \delta \mathrm{T}$ cell subset for effective cancer treatment.

In the context of immunotherapy, expanded $\gamma \delta \mathrm{T}$ cells for adoptive transfer exhibit an enhanced CD56 expression as well (6). However, this observation was only made in healthy donors. Conversely, $\gamma \delta$ T cells of acute myeloid leukemia patients exhibit already elevated levels of CD56, and after expansion, even a downregulation of CD56 is observed (6). The increased expression of CD56 by $\gamma \delta \mathrm{T}$ cells is also seen in patients with solid tumors, for instance, in $\gamma \delta \mathrm{T}$ cells associated with hepatic metastases of colonic origin (20), and infectious disease, including chronic hepatitis $C$ virus infection (26). Intriguingly, while the proportion of $\mathrm{CD} 56^{+} \gamma \delta \mathrm{T}$ cells dramatically drops in patients with HIV disease, and does not return to normal levels even after prolonged antiretroviral therapy, natural viral suppressors have unaffected $\mathrm{CD}^{2} 6^{+} \gamma \delta \mathrm{T}$ cell levels and function similar to those of healthy controls (24).

\section{Dendritic Cells}

Given their primary function to capture, process, and present antigens to T cells, DCs play a critical role in stimulating adaptive (antigen-specific) immunity. In general, lytic effector functions are not classically attributed to DCs. However, it is has been demonstrated that both plasmacytoid and myeloid DCs can adapt a $\mathrm{CD} 56^{+}$phenotype and acquire cytotoxic functions (5). Plasmacytoid DCs activated by the tick-borne encephalitis vaccine Frühsommer meningoencephalitis display high CD56 expression, coinciding with elevated expression of programmed death-ligand 1, granzyme B, TNF-related apoptosis-inducing ligand (TRAIL), and effector functions. Interestingly, neutralizing CD56 did not result in diminished specific lysis of tumor cells (74). Furthermore, CD56 ${ }^{+}$monocyte-derived IL-15 DCs possess a more pronounced lytic effector function toward tumor cells as compared to their $\mathrm{CD}^{-} 6^{-}$counterparts, accompanied by elevated TRAIL and granzyme B levels, as well as a superior antigen-presenting capacity (75). Similarly, CD56 ${ }^{+}$ IFN- $\alpha$ DCs exhibit a TRAIL-mediated cytolytic activity against tumor cells (76). Apart from exerting a direct cytolytic activity, CD56 ${ }^{+}$DCs have potent antigen-presenting capacity as well (74-76) and are particularly effective at inducing innate lymphocyte activation $(41,77,78)$. Unfortunately, malignant cells seem to disable these DC subsets $(18,76)$. CD56 ${ }^{+}$expression on plasmacytoid and myeloid DCs is downregulated subsequent to contact with head and neck squamous cell carcinoma cells in vitro, and $\mathrm{CD}^{+} 6^{+} \mathrm{DC}$ subsets are absent in metastatic lymph nodes $(18,76)$.

\section{Monocytes}

One important function of monocytes is their contribution to the renewal of DCs (and some tissue macrophages) predominantly under inflammatory conditions. CD $14^{+} \mathrm{CD} 56^{+}$ monocytes, which could function as potential precursors of $\mathrm{CD} 56^{+} \mathrm{DCs}$, have been found in human peripheral blood (14). They are able to infiltrate into tumor lesions and have a direct cytolytic activity toward malignant cells upon activation (14). Interestingly, cancer patients, both with solid tumors and hematological malignancies, reveal much higher numbers of this monocyte subset as compared to healthy controls (14). However, a negative correlation exists between the magnitude of tumor spread and the amount of $\mathrm{CD}^{+} 6^{+}$monocytes (14). This possibly points to the fact that these cells might play a role in immune tolerance or, in analogy with DCs, that $\mathrm{CD}^{2} 6^{+}$monocytes are being downregulated by the tumor environment (79). Consonant with the increased prevalence of $\mathrm{CD}_{56}{ }^{+}$monocytes in cancer patients, this subset is also found elevated in autoimmune diseases, such as Crohn's disease and rheumatoid arthritis $(29,34)$. From a therapeutic point of view, patients with rheumatoid arthritis treated with etanercept, a TNF- $\alpha$ inhibitor, show a decline in the $\mathrm{CD}^{+} 6^{+}$monocyte subset, associated with a better response to treatment (34). This is in line with the assumption that $\mathrm{CD} 56^{+}$monocytes are being part of the activated cellular immune response.

\section{CD56 EXPRESSION IN OTHER SPECIES}

Given the fact that many laboratory animals are used as preclinical models for human disease or basic biomedical research, a brief overview of CD56 expression in other species is warranted, especially since patterns of CD56 expression differ markedly from those found in humans. NK cells of rodents, for example, 
the most commonly used small animals, do not express CD56 at all. Instead, they are generally identified by their expression of DX5/CD49b or NKR-P1C in mice, or NKR-P1A in rats, in the absence of CD3 (80). Of note, recent data indicate a developmental or lineage relationship between mouse ILCs and human blood CD56 $6^{\text {bright }} \mathrm{NK}$ cells, while signature genes of mouse NK cells turned out to be enriched in human CD56 ${ }^{\text {dim }}$ NK cells (81). However, the current debate on NK cell vs ILC types $(82,83)$ is beyond the scope of this review. Despite exhibiting far greater similarities to human NK cells, as compared to rodent NK cells, NK cells of non-human primates, such as cynomolgus and rhesus macaques, generally lack CD56 expression as well $(84,85)$. On the other hand, the majority of monocytes of non-human primates do express CD56 $(85,86)$. Considering CD56 protein expression on immune cells seems to be highly interspecies dependent, it remains to be addressed whether there is a specific functional role for this molecule on (human) immune cells.

\section{UPREGULATION, BINDING INTERACTIONS, AND FUNCTIONALITY}

As stated above, there is a body of evidence that CD56 expression is often associated with activation or cytotoxicity in immune cells. This brings forward the question as to whether CD56 is merely an indicator/marker of an activated cell state or if it is actively involved in immune effector function. Moreover, in view of future target discovery for immunotherapy, it is interesting to elucidate which molecular processes give rise to the expression of this molecule. In this context it has been shown that the proportion of the subset of $\mathrm{T}$ cells expressing surface CD56 was drastically reduced in IL-12/23 axis-deficient patients, suggesting that the presence of IL-12/23 is mandatory for the expansion of $\mathrm{CD}_{56} 6^{+} \mathrm{T}$ cells (53). Of course, this finding does not prove that IL-12/23 stimulation leads to the direct upregulation of CD56, especially since these patients did not show alterations in their CD56 $6^{\mathrm{dim} / \text { bright }} \mathrm{NK}$ cells subsets (53). On the other hand, culturing NK cells with IL-15 leads to an upregulation of CD56 on both CD56 $6^{\text {bright }}$ and CD $56^{\text {dim }} \mathrm{NK}$ cells, concomitant with enhanced expression of NK cell activating receptors NKG2D, NKp30, and NKp46 (87). The same shifts in phenotype are also observed in allogeneic HSCT patients, whereby the greatest changes were observed in the early posttransplant months, a period in which IL-15 levels peak (87). In addition, there is evidence that CD56 expression on CD56 ${ }^{-}$ $\mathrm{T}$ cells can be induced by IL-15 stimulation (54). Purified $\mathrm{CD}^{+} \mathrm{CD}^{-} \mathrm{T} 6^{-}$cells express de novo CD56 after 12 days of culture with IL-15 (54). Likewise, umbilical cord blood T cells acquire CD56 after culture in IL-15 (56). Therefore, with some certainty, it can be stated that the pleiotropic cytokine IL-15, a well-documented regulator of homeostasis and activation of both innate and adaptive immunity, induces the expression of CD56 on immune cells bearing the IL-2/IL-15R $\beta$ unit such as NK cells and T cells $(88,89)$. However, the exact mechanism remains unclear. Besides, based on the available literature on this subject, it is unlikely that IL-15 is the only factor capable of having a direct effect on the expression on CD56. For example, similar effects on CD56 expression have been described for CD3/TCR-mediated activation of T cells (4).

On a molecular level, long non-coding (lnc) RNAs orchestrate genetic regulatory outputs, participating in cell differentiation and function (90). Recently, lncRNA AB128931 or lnc-CD56 has been discovered in NK cells, positively correlating with CD56 expression (91). Also, lnc-CD56 knockdown reduces CD56 transcription, providing evidence that lnc-CD56 functions as a positive regulator of CD56 (91). Additional data are however required to unequivocally confirm the roles for this lncRNA in CD56 expression by immune cells in general.

Lastly, from a functional viewpoint, unfortunately, to date, very little is known regarding the functional role of CD56 on immune cells. One key function in the development of NK cells is the CD56-driven migratory behavior of NK cells on stromal cells, forming a developmental synapse (92). NK cells acquire motility with progressive maturation, correlated with the expression of CD56 on developing NK cells. Blocking of CD56 therefore perturbs both NK cell motility and maturation (92). $\mathrm{CD} 6^{+}$immune cells are also able to form strong immune synapses with each other through CD56 binding. For example, $\mathrm{CD}^{2} 6^{+} \mathrm{DCs}$ have been shown to induce the preferential activation and expansion of $\mathrm{CD}^{+} 6^{+} \gamma \delta \mathrm{T}$ cells via CD56 (93). In particular, homophilic interaction between CD56 molecules on $\mathrm{CD} 6^{+}$cells can be formed, including immune cells but also, for example, tumor cells. In this way, $\mathrm{CD} 56^{+} \mathrm{CIK}$ cells are able to kill CD56+ leukemic cells (94). This implies that knocking down CD56 on effector cells makes them less cytotoxic against CD56 ${ }^{+}$ target cells and, conversely, that downregulating CD56 on target cells impedes CD56-mediated lysis (94).

\section{CONCLUSION AND FUTURE PERSPECTIVES}

Hematopoietic expression of CD56 seems to be confined to activated immune cells exhibiting some level of cytotoxic properties. It is therefore tempting to speculate that CD56 is not merely a phenotypic marker of NK cells. $\alpha \beta$ T cells, $\gamma \delta$ T cells, DCs, monocytes, and possibly even more cells of the immune system can upregulate or neo-express CD56 when activated. This implies some concerns regarding current scientific research. For example, it would be recommended to reconsider the use of negative selection kits making use of CD56 as a depletion marker for NK cells. Chances are that besides the removal of NK cells also other valuable (activated) $\mathrm{CD} 6^{+}$white blood cell types will be depleted impacting on the applied assay. Furthermore, in current clinical trials cancer patients with $\mathrm{CD} 56^{+}$tumors are being treated with lorvotuzumab mertansine, a CD56-targeting antibody-drug (95). Although in preclinical studies lorvotuzumab was shown to be promising in the treatment of CD56-positive tumors, these results were not entirely translatable to the human situation. A major adverse event was the rate of infection and infectionrelated deaths upon addition of lorvotuzumab to etoposide/ carboplatin therapy in patients with small cell lung cancer (95). The combination of agents with known hematologic toxicities is a risk, but potentially the depletion of $\mathrm{CD} 56^{+}$immune cells holds an even greater risk. It is evident that more research is warranted 
on the role of CD56 expression in cells of the immune system. Clarifying the upregulation and functional role of CD56 on immune cells should therefore be considered a priority, considering current and future immune therapeutic options will most likely benefit from it.

\section{AUTHOR CONTRIBUTIONS}

HVA researched the data, wrote the review, and designed the figure. AC, ES, and VVT reviewed and revised the manuscript for intellectual content.

\section{REFERENCES}

1. Ditlevsen DK, Povlsen GK, Berezin V, Bock E. NCAM-induced intracellular signaling revisited. J Neurosci Res (2008) 86(4):727-43. doi:10.1002/jnr.21551

2. Maness PF, Schachner M. Neural recognition molecules of the immunoglobulin superfamily: signaling transducers of axon guidance and neuronal migration. Nat Neurosci (2007) 10(1):19-26. doi:10.1038/nn1827

3. Cheng M, Chen Y, Xiao W, Sun R, Tian Z. NK cell-based immunotherapy for malignant diseases. Cell Mol Immunol (2013) 10(3):230-52. doi:10.1038/ cmi.2013.10

4. Kelly-Rogers J, Madrigal-Estebas L, O'Connor T, Doherty DG. Activationinduced expression of CD56 by T cells is associated with a reprogramming of cytolytic activity and cytokine secretion profile in vitro. Hum Immunol (2006) 67(11):863-73. doi:10.1016/j.humimm.2006.08.292

5. Roothans D, Smits E, Lion E, Tel J, Anguille S. CD56 marks human dendritic cell subsets with cytotoxic potential. Oncoimmunology (2013) 2(2):e23037. doi:10.4161/onci.23037

6. Van Acker HH, Anguille S, Willemen Y, Van den Bergh JM, Berneman ZN, Lion E, et al. Interleukin-15 enhances the proliferation, stimulatory phenotype, and antitumor effector functions of human gamma delta T cells. J Hematol Oncol (2016) 9(1):101. doi:10.1186/s13045-016-0329-3

7. Kato J, Hisha H, Wang XL, Mizokami T, Okazaki S, Li Q, et al. Contribution of neural cell adhesion molecule (NCAM) to hemopoietic system in monkeys. Ann Hematol (2008) 87(10):797-807. doi:10.1007/s00277-008-0513-9

8. Skog MS, Nystedt J, Korhonen M, Anderson H, Lehti TA, Pajunen MI, et al. Expression of neural cell adhesion molecule and polysialic acid in human bone marrow-derived mesenchymal stromal cells. Stem Cell Res Ther (2016) 7(1):113. doi:10.1186/s13287-016-0373-5

9. Xu S, Li X, Zhang J, Chen J. Prognostic value of CD56 in patients with acute myeloid leukemia: a meta-analysis. JCancer Res Clin Oncol (2015) 141(10):1859-70. doi:10.1007/s00432-015-1977-3

10. Pan Y, Wang H, Tao Q, Zhang C, Yang D, Qin H, et al. Absence of both CD56 and CD117 expression on malignant plasma cells is related with a poor prognosis in patients with newly diagnosed multiple myeloma. Leuk Res (2016) 40:77-82. doi:10.1016/j.leukres.2015.11.003

11. He H, Luthringer DJ, Hui P, Lau SK, Weiss LM, Chu PG. Expression of CD56 and WT1 in ovarian stroma and ovarian stromal tumors. Am J Surg Pathol (2008) 32(6):884-90. doi:10.1097/PAS.0b013e3181609d59

12. Teicher BA. Targets in small cell lung cancer. Biochem Pharmacol (2014) 87(2):211-9. doi:10.1016/j.bcp.2013.09.014

13. Pressey JG, Adams J, Harkins L, Kelly D, You Z, Lamb LS Jr. In vivo expansion and activation of gammadelta $\mathrm{T}$ cells as immunotherapy for refractory neuroblastoma: a phase 1 study. Medicine (Baltimore) (2016) 95(39):e4909. doi:10.1097/MD.0000000000004909

14. Papewalis C, Jacobs B, Baran AM, Ehlers M, Stoecklein NH, Willenberg HS, et al. Increased numbers of tumor-lysing monocytes in cancer patients. Mol Cell Endocrinol (2011) 337(1-2):52-61. doi:10.1016/j.mce.2011.01.020

15. Ribas A, Shin DS, Zaretsky J, Frederiksen J, Cornish A, Avramis E, et al. PD-1 blockade expands intratumoral memory T cells. Cancer Immunol Res (2016) 4(3):194-203. doi:10.1158/2326-6066.CIR-15-0210

16. Hasumi K, Aoki Y, Wantanabe R, Mann DL. Clinical response of advanced cancer patients to cellular immunotherapy and intensity-modulated radiation therapy. Oncoimmunology (2013) 2(10):e26381. doi:10.4161/onci.26381

\section{ACKNOWLEDGMENTS}

This work was supported by a grant of the Research Foundation Flanders (FWO Vlaanderen, http://www.fwo.be, grant number G039914N). HVA holds a PhD fellowship of the FWO and received a travel grant for a long stay abroad of the FWO. AC is a Clinical Training Fellow supported by grants from the Wellcome Trust, Great Ormond Street Hospital Children's Charity, and Great Ormond Street Hospital Biomedical Research Center. The authors would like to thank Dr. Sébastien Anguille and Sara I. Van Acker for their contribution to Figure 1.

17. Garcia-Cuesta EM, Esteso G, Ashiru O, Lopez-Cobo S, Alvarez-Maestro M, Linares A, et al. Characterization of a human anti-tumoral NK cell population expanded after BCG treatment of leukocytes. Oncoimmunology (2017) 6(4):e1293212. doi:10.1080/2162402X.2017.1293212

18. Thiel A, Kesselring R, Pries R, Wittkopf N, Puzik A, Wollenberg B. Plasmacytoid dendritic cell subpopulations in head and neck squamous cell carcinoma. Oncol Rep (2011) 26(3):615-20. doi:10.3892/or.2011.1350

19. Li X, Peng J, Pang Y, Yu S, Yu X, Chen P, et al. Identification of a FOXP3(+) $\mathrm{CD} 3(+) \mathrm{CD} 56(+)$ population with immunosuppressive function in cancer tissues of human hepatocellular carcinoma. Sci Rep (2015) 5:14757. doi:10.1038/ srep14757

20. Kenna T, Golden-Mason L, Norris S, Hegarty JE, O'Farrelly C, Doherty DG. Distinct subpopulations of gamma delta $\mathrm{T}$ cells are present in normal and tumor-bearing human liver. Clin Immunol (2004) 113(1):56-63. doi:10.1016/j. clim.2004.05.003

21. Richter J, Neparidze N, Zhang L, Nair S, Monesmith T, Sundaram R, et al. Clinical regressions and broad immune activation following combination therapy targeting human NKT cells in myeloma. Blood (2013) 121(3):423-30. doi:10.1182/blood-2012-06-435503

22. Mavilio D, Lombardo G, Benjamin J, Kim D, Follman D, Marcenaro E, et al. Characterization of CD56-/CD16+ natural killer (NK) cells: a highly dysfunctional NK subset expanded in HIV-infected viremic individuals. Proc Natl Acad Sci U S A (2005) 102(8):2886-91. doi:10.1073/pnas.0409872102

23. Poonia B, Pauza CD. Levels of CD56+TIM-3- effector CD8 T cells distinguish HIV natural virus suppressors from patients receiving antiretroviral therapy. PLoS One (2014) 9(2):e88884. doi:10.1371/journal.pone.0088884

24. Riedel DJ, Sajadi MM, Armstrong CL, Cummings JS, Cairo C, Redfield RR, et al. Natural viral suppressors of HIV-1 have a unique capacity to maintain gammadelta T cells. AIDS (2009) 23(15):1955-64. doi:10.1097/ QAD.0b013e32832ff1ff

25. Bjorkstrom NK, Ljunggren HG, Sandberg JK. CD56 negative NK cells: origin, function, and role in chronic viral disease. Trends Immunol (2010) 31(11):401-6. doi:10.1016/j.it.2010.08.003

26. Yin W, Tong S, Zhang Q, Shao J, Liu Q, Peng H, et al. Functional dichotomy of Vdelta2 gammadelta $\mathrm{T}$ cells in chronic hepatitis $\mathrm{C}$ virus infections: role in cytotoxicity but not for IFN-gamma production. Sci Rep (2016) 6:26296. doi:10.1038/srep26296

27. Della Chiesa M, Falco M, Podesta M, Locatelli F, Moretta L, Frassoni F, et al. Phenotypic and functional heterogeneity of human NK cells developing after umbilical cord blood transplantation: a role for human cytomegalovirus? Blood (2012) 119(2):399-410. doi:10.1182/blood-2011-08-372003

28. Bjorkstrom NK, Lindgren T, Stoltz M, Fauriat C, Braun M, Evander M, et al. Rapid expansion and long-term persistence of elevated NK cell numbers in humans infected with hantavirus. J Exp Med (2011) 208(1):13-21. doi:10.1084/ jem. 20100762

29. Grip O, Bredberg A, Lindgren S, Henriksson G. Increased subpopulations of CD16(+) and CD56(+) blood monocytes in patients with active Crohn's disease. Inflamm Bowel Dis (2007) 13(5):566-72. doi:10.1002/ibd.20025

30. Zaguia F, Saikali P, Ludwin S, Newcombe J, Beauseigle D, McCrea E, et al. Cytotoxic NKG2C+CD4 T cells target oligodendrocytes in multiple sclerosis. J Immunol (2013) 190(6):2510-8. doi:10.4049/jimmunol.1202725

31. Fujii C, Kondo T, Ochi H, Okada Y, Hashi Y, Adachi T, et al. Altered $\mathrm{T}$ cell phenotypes associated with clinical relapse of multiple sclerosis 
patients receiving fingolimod therapy. Sci Rep (2016) 6:35314. doi:10.1038/ srep35314

32. Koreck A, Suranyi A, Szony BJ, Farkas A, Bata-Csorgo Z, Kemeny L, et al. $\mathrm{CD} 3+\mathrm{CD} 56+\mathrm{NK} \mathrm{T}$ cells are significantly decreased in the peripheral blood of patients with psoriasis. Clin Exp Immunol (2002) 127(1):176-82. doi:10.1046/j.1365-2249.2002.01721.x

33. Nguyen S, Morel V, Le Garff-Tavernier M, Bolgert F, Leblond V, Debre P, et al. Persistence of CD16+/CD56-/2B4+ natural killer cells: a highly dysfunctional NK subset expanded in ocular myasthenia gravis. J Neuroimmunol (2006) 179(1-2):117-25. doi:10.1016/j.jneuroim.2006.05.028

34. Krasselt M, Baerwald C, Wagner U, Rossol M. CD56+ monocytes have a dysregulated cytokine response to lipopolysaccharide and accumulate in rheumatoid arthritis and immunosenescence. Arthritis Res Ther (2013) 15(5):R139. doi:10.1186/ar4321

35. Long EO, Kim HS, Liu D, Peterson ME, Rajagopalan S. Controlling natural killer cell responses: integration of signals for activation and inhibition. Annu Rev Immunol (2013) 31:227-58. doi:10.1146/annurev-immunol-020711-075005

36. Ruggeri L, Capanni M, Urbani E, Perruccio K, Shlomchik WD, Tosti A, et al. Effectiveness of donor natural killer cell alloreactivity in mismatched hematopoietic transplants. Science (2002) 295(5562):2097-100. doi:10.1126/ science. 1068440

37. Chouaib S, Pittari G, Nanbakhsh A, El Ayoubi H, Amsellem S, Bourhis JH, et al. Improving the outcome of leukemia by natural killer cell-based immunotherapeutic strategies. Front Immunol (2014) 5:95. doi:10.3389/ fimmu.2014.00095

38. Rezvani K, Rouce RH. The application of natural killer cell immunotherapy for the treatment of cancer. Front Immunol (2015) 6:578. doi:10.3389/ fimmu.2015.00578

39. Bontkes HJ, Kramer D, Ruizendaal JJ, Meijer CJ, Hooijberg E. Tumor associated antigen and interleukin-12 mRNA transfected dendritic cells enhance effector function of natural killer cells and antigen specific T-cells. Clin Immunol (2008) 127(3):375-84. doi:10.1016/j.clim.2008.02.001

40. Liu Y, Wu HW, Sheard MA, Sposto R, Somanchi SS, Cooper LJ, et al. Growth and activation of natural killer cells ex vivo from children with neuroblastoma for adoptive cell therapy. Clin Cancer Res (2013) 19(8):2132-43. doi:10.1158/1078-0432.CCR-12-1243

41. Anguille S, Van Acker HH, Van den Bergh J, Willemen Y, Goossens H, Van Tendeloo VF, et al. Interleukin-15 dendritic cells harness NK cell cytotoxic effector function in a contact- and IL-15-dependent manner. PLoS One (2015) 10(5):e0123340. doi:10.1371/journal.pone.0123340

42. Spallanzani RG, Torres NI, Avila DE, Ziblat A, Iraolagoitia XL, Rossi LE, et al. Regulatory dendritic cells restrain NK Cell IFN-gamma production through mechanisms involving NKp46, IL-10, and MHC class I-specific inhibitory receptors. J Immunol (2015) 195(5):2141-8. doi:10.4049/jimmunol.1403161

43. Loza MJ, Perussia B. The IL-12 signature: NK cell terminal CD56+high stage and effector functions. J Immunol (2004) 172(1):88-96. doi:10.4049/ jimmunol.172.1.88

44. Vukicevic M, Chalandon Y, Helg C, Matthes T, Dantin C, Huard B, et al. CD56bright NK cells after hematopoietic stem cell transplantation are activated mature NK cells that expand in patients with low numbers of T cells. Eur J Immunol (2010) 40(11):3246-54. doi:10.1002/eji.200940016

45. Reiners KS, Topolar D, Henke A, Simhadri VR, Kessler J, Sauer M, et al. Soluble ligands for NK cell receptors promote evasion of chronic lymphocytic leukemia cells from NK cell anti-tumor activity. Blood (2013) 121(18):3658-65. doi:10.1182/blood-2013-01-476606

46. Lugini L, Cecchetti S, Huber V, Luciani F, Macchia G, Spadaro F, et al. Immune surveillance properties of human NK cell-derived exosomes. J Immunol (2012) 189(6):2833-42. doi:10.4049/jimmunol.1101988

47. Segura E, Nicco C, Lombard B, Veron P, Raposo G, Batteux F, et al. ICAM-1 on exosomes from mature dendritic cells is critical for efficient naive T-cell priming. Blood (2005) 106(1):216-23. doi:10.1182/blood-2005-01-0220

48. Jacobson A, Bell F, Lejarcegui N, Mitchell C, Frenkel L, Horton H. Healthy neonates possess a CD56-negative NK cell population with reduced anti-viral activity. PLoS One (2013) 8(6):e67700. doi:10.1371/journal.pone.0067700

49. Lu X, Kondo Y, Takamatsu H, Ohata K, Yamazaki H, Takami A, et al. CD16+ CD56- NK cells in the peripheral blood of cord blood transplant recipients: a unique subset of NK cells possibly associated with graft-versus-leukemia effect. Eur J Haematol (2008) 81(1):18-25. doi:10.1111/j.16000609.2008.01073.x
50. De Angelis C, Mancusi A, Ruggeri L, Capanni M, Urbani E, Velardi A, et al. Expansion of CD56-negative, CD16-positive, KIR-expressing natural killer cells after $\mathrm{T}$ cell-depleted haploidentical hematopoietic stem cell transplantation. Acta Haematol (2011) 126(1):13-20. doi:10.1159/000323661

51. Campos C, Pera A, Sanchez-Correa B, Alonso C, Lopez-Fernandez I, Morgado S, et al. Effect of age and CMV on NK cell subpopulations. Exp Gerontol (2014) 54:130-7. doi:10.1016/j.exger.2014.01.008

52. Cohavy O, Targan SR. CD56 marks an effector T cell subset in the human intestine. J Immunol (2007) 178(9):5524-32. doi:10.4049/jimmunol.178.9.5524

53. Guia S, Cognet C, de Beaucoudrey L, Tessmer MS, Jouanguy E, Berger C, et al. A role for interleukin-12/23 in the maturation of human natural killer and CD56+ T cells in vivo. Blood (2008) 111(10):5008-16. doi:10.1182/ blood-2007-11-122259

54. Correia MP, Costa AV, Uhrberg M, Cardoso EM, Arosa FA. IL-15 induces $\mathrm{CD} 8+\mathrm{T}$ cells to acquire functional NK receptors capable of modulating cytotoxicity and cytokine secretion. Immunobiology (2011) 216(5):604-12. doi:10.1016/j.imbio.2010.09.012

55. Pittet MJ, Speiser DE, Valmori D, Cerottini JC, Romero P. Cutting edge: cytolytic effector function in human circulating CD8+ $\mathrm{T}$ cells closely correlates with CD56 surface expression. J Immunol (2000) 164(3):1148-52. doi:10.4049/jimmunol.164.3.1148

56. Tang Q, Grzywacz B, Wang H, Kataria N, Cao Q, Wagner JE, et al. Umbilical cord blood T cells express multiple natural cytotoxicity receptors after IL-15 stimulation, but only NKp30 is functional. J Immunol (2008) 181(7):4507-15. doi:10.4049/jimmunol.181.7.4507

57. Chan WK, Rujkijyanont P, Neale G, Yang J, Bari R, Das Gupta N, et al. Multiplex and genome-wide analyses reveal distinctive properties of KIR+ and CD56+ T cells in human blood. J Immunol (2013) 191(4):1625-36. doi:10.4049/jimmunol.1300111

58. Mesiano G, Todorovic M, Gammaitoni L, Leuci V, Giraudo Diego L, Carnevale-Schianca F, et al. Cytokine-induced killer (CIK) cells as feasible and effective adoptive immunotherapy for the treatment of solid tumors. Expert Opin Biol Ther (2012) 12(6):673-84. doi:10.1517/14712598.2012.675323

59. Schmeel FC, Schmeel LC, Gast SM, Schmidt-Wolf IG. Adoptive immunotherapy strategies with cytokine-induced killer (CIK) cells in the treatment of hematological malignancies. Int J Mol Sci (2014) 15(8):14632-48. doi:10.3390/ ijms150814632

60. Almeida I, Silva SV, Fonseca AR, Silva I, Vasconcelos C, Lima M. T and NK cell phenotypic abnormalities in systemic sclerosis: a cohort study and a comprehensive literature review. Clin Rev Allergy Immunol (2015) 49(3):347-69. doi:10.1007/s12016-015-8505-8

61. Pereira BI, Akbar AN. Convergence of innate and adaptive immunity during human aging. Front Immunol (2016) 7:445. doi:10.3389/fimmu.2016.00445

62. Goronzy JJ, Weyand CM. Successful and maladaptive T cell aging. Immunity (2017) 46(3):364-78. doi:10.1016/j.immuni.2017.03.010

63. Waziri A, Killory B, Ogden AT III, Canoll P, Anderson RC, Kent SC, et al. Preferential in situ CD4+CD56+ T cell activation and expansion within human glioblastoma. J Immunol (2008) 180(11):7673-80. doi:10.4049/ jimmunol.180.11.7673

64. Fisher J, Kramer AM, Gustafsson K, Anderson J. Non-V delta 2 gamma delta $\mathrm{T}$ lymphocytes as effectors of cancer immunotherapy. Oncoimmunology (2015) 4(3):e973808. doi:10.4161/2162402X.2014.973808

65. Van Acker HH, Anguille S, Van Tendeloo VF, Lion E. Empowering gamma delta $\mathrm{T}$ cells with antitumor immunity by dendritic cell-based immunotherapy. Oncoimmunology (2015) 4(8):e1021538. doi:10.1080/2162402X.2015.1021538

66. Fay NS, Larson EC, Jameson JM. Chronic inflammation and gammadelta T cells. Front Immunol (2016) 7:210. doi:10.3389/fimmu.2016.00210

67. Paul S, Lal G. Regulatory and effector functions of gamma-delta (gammadelta) $\mathrm{T}$ cells and their therapeutic potential in adoptive cellular therapy for cancer. Int J Cancer (2016) 139(5):976-85. doi:10.1002/ijc.30109

68. Born WK, Kemal Aydintug M, O’Brien RL. Diversity of gammadelta T-cell antigens. Cell Mol Immunol (2013) 10(1):13-20. doi:10.1038/cmi.2012.45

69. Dar AA, Patil RS, Chiplunkar SV. Insights into the relationship between toll like receptors and gamma delta T cell responses. Front Immunol (2014) 5:366. doi:10.3389/fimmu.2014.00366

70. Van Acker HH, Anguille S, Willemen Y, Smits EL, Van Tendeloo VF. Bisphosphonates for cancer treatment: mechanisms of action and lessons from clinical trials. Pharmacol Ther (2016) 158:24-40. doi:10.1016/j. pharmthera.2015.11.008 
71. Gruenbacher G, Nussbaumer O, Gander H, Steiner B, Leonhartsberger N, Thurnher M. Stress-related and homeostatic cytokines regulate Vgamma9Vdelta2 T-cell surveillance of mevalonate metabolism. Oncoimmunology (2014) 3(8):e953410. doi:10.4161/21624011.2014.953410

72. Murday AS, Chaudhry S, Pauza CD. Interleukin-18 activates Vg9Vd2+ T cells from HIV+ individuals: recovering the response to phosphoantigen. Immunology (2017) 151(4):385-94. doi:10.1111/imm.12735

73. Alexander AA, Maniar A, Cummings JS, Hebbeler AM, Schulze DH, Gastman BR, et al. Isopentenyl pyrophosphate-activated CD56+ \{gamma\} \{delta\} T lymphocytes display potent antitumor activity toward human squamous cell carcinoma. Clin Cancer Res (2008) 14(13):4232-40. doi:10.1158/ 1078-0432.CCR-07-4912

74. Tel J, Smits EL, Anguille S, Joshi RN, Figdor CG, de Vries IJ. Human plasmacytoid dendritic cells are equipped with antigen-presenting and tumoricidal capacities. Blood (2012) 120(19):3936-44. doi:10.1182/blood-2012-06-435941

75. Anguille S, Lion E, Tel J, de Vries IJ, Coudere K, Fromm PD, et al. Interleukin15-induced CD56(+) myeloid dendritic cells combine potent tumor antigen presentation with direct tumoricidal potential. PLoS One (2012) 7(12):e51851. doi:10.1371/journal.pone.0051851

76. Papewalis C, Jacobs B, Wuttke M, Ullrich E, Baehring T, Fenk R, et al. IFNalpha skews monocytes into CD56+-expressing dendritic cells with potent functional activities in vitro and in vivo. J Immunol (2008) 180(3):1462-70. doi:10.4049/jimmunol.180.3.1462

77. Gruenbacher G, Gander H, Rahm A, Nussbaumer W, Romani N, Thurnher M. CD56+ human blood dendritic cells effectively promote TH1type gammadelta T-cell responses. Blood (2009) 114(20):4422-31. doi:10.1182/ blood-2009-06-227256

78. Gruenbacher G, Gander H, Nussbaumer O, Nussbaumer W, Rahm A, Thurnher M. IL-2 costimulation enables statin-mediated activation of human NK cells, preferentially through a mechanism involving CD56+ dendritic cells. Cancer Res (2010) 70(23):9611-20. doi:10.1158/0008-5472.CAN-10-1968

79. Kusmartsev S, Gabrilovich DI. Effect of tumor-derived cytokines and growth factors on differentiation and immune suppressive features of myeloid cells in cancer. Cancer Metastasis Rev (2006) 25(3):323-31. doi:10.1007/s10555-0069002-6

80. Inngjerdingen M, Kveberg L, Naper C, Vaage JT. Natural killer cell subsets in man and rodents. Tissue Antigens (2011) 78(2):81-8. doi:10.1111/j.13990039.2011.01714.x

81. Allan DSJ, Cerdeira AS, Ranjan A, Kirkham CL, Aguilar OA, Tanaka M, et al. Transcriptome analysis reveals similarities between human blood CD3CD56bright cells and mouse CD127+ innate lymphoid cells. Sci Rep (2017) 7(1):3501. doi:10.1038/s41598-017-03256-0

82. Artis D, Spits H. The biology of innate lymphoid cells. Nature (2015) 517(7534):293-301. doi:10.1038/nature14189

83. Jiao Y, Huntington ND, Belz GT, Seillet C. Type 1 innate lymphoid cell biology: lessons learnt from natural killer cells. Front Immunol (2016) 7:426. doi:10.3389/fimmu.2016.00426

84. Hong HS, Rajakumar PA, Billingsley JM, Reeves RK, Johnson RP. No monkey business: why studying NK cells in non-human primates pays off. Front Immunol (2013) 4:32. doi:10.3389/fimmu.2013.00032

85. Sathler-Avelar R, Vitelli-Avelar DM, Mattoso-Barbosa AM, Perdigao-deOliveira M, Costa RP, Eloi-Santos SM, et al. Phenotypic features of circulating leukocytes from non-human primates naturally infected with Trypanosoma cruzi resemble the major immunological findings observed in human Chagas disease. PLoS Negl Trop Dis (2016) 10(1):e0004302. doi:10.1371/journal. pntd.0004302

86. Pomplun N, Weisgrau KL, Evans DT, Rakasz EG. OMIP-028: activation panel for Rhesus macaque NK cell subsets. Cytometry A (2015) 87(10):890-3. doi:10.1002/cyto.a.22727

87. Boyiadzis M, Memon S, Carson J, Allen K, Szczepanski MJ, Vance BA, et al. Up-regulation of NK cell activating receptors following allogeneic hematopoietic stem cell transplantation under a lymphodepleting reduced intensity regimen is associated with elevated IL-15 levels. Biol Blood Marrow Transplant (2008) 14(3):290-300. doi:10.1016/j.bbmt.2007.12.490

88. Golden-Mason L, Kelly AM, Doherty DG, Traynor O, McEntee G, Kelly J, et al. Hepatic interleuklin 15 (IL-15) expression: implications for local NK/NKT cell homeostasis and development. Clin Exp Immunol (2004) 138(1):94-101. doi:10.1111/j.1365-2249.2004.02586.x

89. Waldmann TA. Interleukin-15 in the treatment of cancer. Expert Rev Clin Immunol (2014) 10(12):1689-701. doi:10.1586/1744666X.2014.973856

90. Rinn JL, Chang HY. Genome regulation by long noncoding RNAs. Annu Rev Biochem (2012) 81:145-66. doi:10.1146/annurev-biochem-051410-092902

91. Zhang R, Ni F, Fu B, Wu Y, Sun R, Tian Z, et al. A long noncoding RNA positively regulates CD56 in human natural killer cells. Oncotarget (2016) 7(45):72546-58. doi:10.18632/oncotarget.12466

92. Mace EM, Gunesch JT, Dixon A, Orange JS. Human NK cell development requires CD56-mediated motility and formation of the developmental synapse. Nat Commun (2016) 7:12171. doi:10.1038/ncomms12171

93. Nieda M, Terunuma H, Eiraku Y, Deng X, Nicol AJ. Effective induction of melanoma-antigen-specific CD8 $+\mathrm{T}$ cells via Vgamma9gammadelta $\mathrm{T}$ cell expansion by CD56(high+) interferon-alpha-induced dendritic cells. Exp Dermatol (2015) 24(1):35-41. doi:10.1111/exd.12581

94. Valgardsdottir R, Capitanio C, Texido G, Pende D, Cantoni C, Pesenti E, et al. Direct involvement of CD56 in cytokine-induced killer-mediated lysis of CD56+ hematopoietic target cells. Exp Hematol (2014) 42(12):1013-21. e1011. doi:10.1016/j.exphem.2014.08.005

95. Socinski MA, Kaye FJ, Spigel DR, Kudrik FJ, Ponce S, Ellis PM, et al. Phase $1 / 2$ study of the CD56-targeting antibody-drug conjugate lorvotuzumab mertansine (IMGN901) in combination with carboplatin/etoposide in small-cell lung cancer patients with extensive-stage disease. Clin Lung Cancer (2017) 18(1):68-76.e62. doi:10.1016/j.cllc.2016.09.002

Conflict of Interest Statement: The authors declare that the research was conducted in the absence of any commercial or financial relationships that could be construed as a potential conflict of interest.

The reviewer, DR, and handling editor declared their shared affiliation, and the handling editor states that the process nevertheless met the standards of a fair and objective review.

Copyright (c) 2017 Van Acker, Capsomidis, Smits and Van Tendeloo. This is an open-access article distributed under the terms of the Creative Commons Attribution License (CC BY). The use, distribution or reproduction in other forums is permitted, provided the original author(s) or licensor are credited and that the original publication in this journal is cited, in accordance with accepted academic practice. No use, distribution or reproduction is permitted which does not comply with these terms. 